\title{
Beyond the icon: Core cognition and the bounds of perception
}

\section{Sam Clarke (i)}

York University, Toronto, ON, Canada

\section{Correspondence}

Sam Clarke, 247 Lippincott Street, Toronto, ON, M5S 2P4, Canada.

Email: spclarke@yorku.ca

\section{Funding information}

Arts and Humanities Research Council, Grant/Award Number: AHRC DTP Studentship; Procter Fellowship (Princeton University); VISTA Fellowship at York University, Toronto
This paper refines a controversial proposal: That core systems belong to a perceptual kind, marked by the format of its representational outputs. Following Susan Carey, this proposal has been understood in terms of core representations having an iconic format, like certain paradigmatically perceptual outputs. I argue that they do not, but suggest that the proposal may be better formulated in terms of a broader analogue format type. Formulated in this way, the proposal accommodates the existence of genuine icons in perception, and avoids otherwise troubling objections.

\section{K E Y W O R D S}

analogue representation, Carey (Susan), core cognition, iconic representation, perception, representational format

\section{1 | INTRODUCTION}

In The origin of concepts, Susan Carey (2009) proposes that humans are endowed with "core systems" for the representation of objects, numerosities and agents. ${ }^{1}$ As she characterises them, these are akin to paradigmatically perceptual systems in two ways:

1 In being modular (p. 11).

2 In producing representations with an iconic format (p. 458).

This is striking. The properties that core systems track and represent (e.g., agency and numerosity) seem quite unlike those that might be deemed straightforwardly perceptible (e. g., colour and shape). Yet, modularity and iconicity have both been seen to provide independently plausible means of demarcating the perceptual (e.g., Block, forthcoming; Fodor, 1983). As such, Carey's characterisation may provide reason to think core systems are-in actual 
fact-perceptual systems, and that their discovery reveals perception to be in the business of attributing high-level properties to the entities it detects (cf., Block, 2014; Burge, 2011). ${ }^{2}$

This would be a significant result. But Carey's characterisation is controversial. Even when we bracket familiar concerns with modularity (e.g., Prinz, 2007), her argument for (2) raises worries of its own. A cursory discussion aside (2009, pp. 459-460), it involves generalising from a single example: The analogue magnitude system, involved in certain forms of numerical core cognition. Believing she has established the iconicity of this single system's outputs, Carey simply "speculates" (p. 458) that all core systems will be like it in producing wholly iconic representations.

Many find this unsatisfactory (e.g., Shea, 2011, p. 131). Perhaps most pointedly, QuiltyDunn (2016, 2017, Green \& Quilty-Dunn, 2017) argues that, even if the analogue magnitude system produces iconic representations, it is implausible to think that Carey's core object system does (see also Kahneman, Treisman \& Gibbs, 1992; Spelke, 1988). Since core object representations facilitate certain forms of numerical core cognition (Feigenson \& Carey, 2003) and underwrite the core cognition of agency (van Buren, Gao \& Scholl, 2017), this suggests that the supposed iconicity of the analogue magnitude system's outputs fails to generalise to Carey's other core systems. For those emphasising a common representational format when demarcating perception, this has been seen to indicate that core systems do not qualify as such (e.g., Spelke, 1988). Meanwhile, for those who have sought to demarcate perception in other ways (e. g., by appeal to modularity) this has been seen to indicate that perception cannot be usefully demarcated by the format of its representations full stop (e.g., Quilty-Dunn, 2016, p. 262).

I wish to paint a different picture. Like the aforementioned, I find reason to doubt Carey's suggestion that core systems produce wholly iconic outputs. Indeed, I go further: I find reason to doubt Carey's suggestion that the analogue magnitude system-her flagship example of a core system with iconic outputs-produces outputs of this sort. Instead, I propose that it produces representations with a non-iconic, yet wholly "analogue," format. But, while this sounds like bad news for those who deem core systems perceptual, in large part due to the iconicity of their representational outputs, I suggest that it presents them with an opportunity. This is because various objections to the iconicity of core cognition need not afflict the claim that core cognition produces wholly analogue outputs. Better still, an analogue format (of this sort) appears better able to characterise certain forms of non-visual perceptual representation. Since icons are but one kind of analogue representation, these considerations indicate that appealing to this broader analogue format type provides a superior means of characterising, and perhaps demarcating, the relevant perceptual kind.

I proceed as follows: In Section 2, I introduce the term "iconic representation," noting a necessary condition on a representation's qualification as such. In Section 3, I consider Carey's flagship example of a core system that produces iconic representations-the analogue magnitude system. While this system's representations are icon-like in having an analogue format, I argue that they are unlikely to meet the necessary condition exposed in Section 2. This reveals that, even here, we should reject the suggestion that core cognition is iconic. In Section 4, I motivate the possibility that core/perceptual representations are demarcated by having this analogue (but not necessarily iconic) format. To this end, I note that an analogue format seems better able to characterise nonvisual perception; suggest that characterising perception in terms of an analogue format avoids

\footnotetext{
${ }^{2}$ Carey may object to framing things in this way (Carey, 2009, p.10; but see Carey, 2011). To some extent, this is wordplay-the term "perception" may be used in a variety of different ways, and there may be various kinds in the vicinity (Phillips, forthcoming). But, insofar as independently plausible marks of the perceptual converge in core systems there is reason to think these perceptual in some substantive sense.
} 
prominent objections to the iconicity of core/perceptual object representations; and provide reason to doubt that non-perceptual cognitive representations qualify as such.

\section{2 | ICONIC REPRESENTATION: A NECESSARY CONDITION}

Representational formats are types of representational structure. They differ in how they make information "explicit and accessible" (Kosslyn, Thompson \& Ganis, 2006, p. 8; Marr, 1982, pp. 2022). In this respect, an important and widely acknowledged fact about representations with an iconic format is that they conform to the "picture principle" (see Carey, 2009, p. 135; Fodor, 2007, p. 108). ${ }^{3}$ Minimally, this concerns the suggestion that if $\mathrm{R}$ is an icon representing $\mathrm{X}$, then:

(PP) parts of $\mathrm{R}$ represent parts of $\mathrm{X}$ with structural relations between parts of $\mathrm{R}$ representing structural relations between parts of $\mathrm{X} .{ }^{4}$

Take Figure 1. Here, a paradigmatic icon (a photograph) represents Jerry Fodor. In so doing, spatial parts of the representation represent spatial parts of Fodor (e.g., his eyes and nose), with structural relations between these parts of the representation representing structural relations between the relevant parts of Fodor. In this way, the representation conforms to PP, with information about parts of the represented entity, and their relationship to one another, being made "explicit" and "accessible" by the representation.

Of course, Figure 1 is just one example. Nevertheless, it is unexceptional in this regard. PP is widely seen to characterise iconic representations quite generally (see Echeverri, 2017; Fodor, 2007; Green \& Quilty-Dunn, 2017; Johnson-Laird, 2001; Kosslyn et al., 2006; Neisser, 1967; Tye, 1991). This is no accident. "Iconic representation" is a technical term, introduced by cognitive scientists to pick out a representational kind that helps explain certain empirical findings. But, crucially, unless a representation conforms to PP it will not be able to help in the intended way. As such, it will not belong to the representational kind that cognitive scientists have found useful to pick out using the label.

To illustrate, consider the famous Sperling (1960) experiments. Here, subjects were briefly presented with an array of nine letters, organised into three rows of three (Figure 2). Their task was to subsequently recall as many of these letters as possible. Typically, subjects would succeed in listing no more than three or four. But, remarkably, when a row was cued for report shortly after it had disappeared from view subjects would succeed in recalling all or nearly all of the letters from that row, no matter which row was cued. This suggested that the subjects' visual systems had registered all (or nearly all) of the letters in the array, despite the subjects' inability to recall all of these after the fact.

Various theorists take this (and related work) to indicate the existence of iconic visual representations that can be briefly stored in visual memory (e.g., Dretske, 1981; Fodor, 2007; Neisser, 1967; Quilty-Dunn, forthcoming). For present purposes, it is not important that this is true (for concerns, see Coltheart, 1980; Gross \& Flombaum, 2017; for response, see QuiltyDunn, forthcoming b). What matters is how an appeal to iconicity purports to make sense of

\footnotetext{
${ }^{3}$ The term "icon" goes at least as far back as C. S. Peirce's division of signs into icons, indexes and symbols. Here, I am concerned with the term as it is used in the cognitive sciences.

${ }^{4}$ Often PP is interpreted more strongly as requiring that the relevant parts of R picture the relevant parts of $\mathrm{X}$

(Fodor, 2007). I am not assuming this here but doing so would only strengthen my conclusion (see Clarke, 2019).
} 


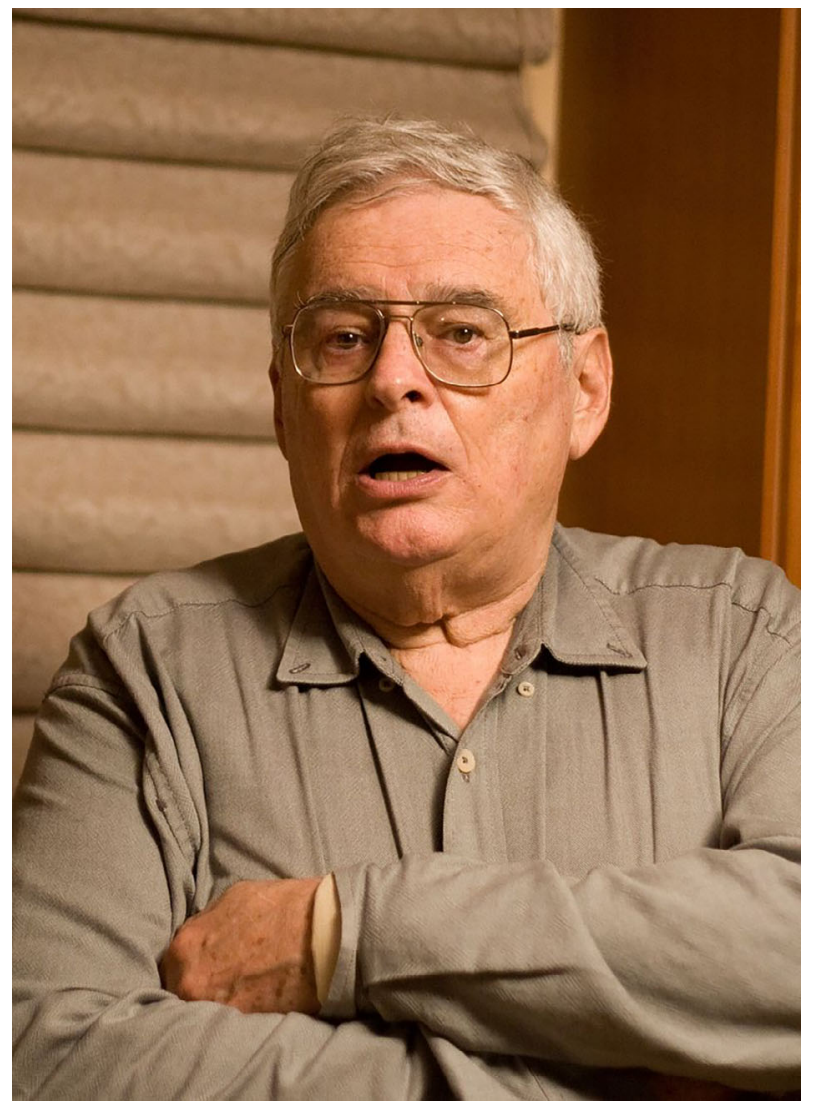

FIG URE 1 Jerry has eyes and a nose [Color figure can be viewed at wileyonlinelibrary.com]

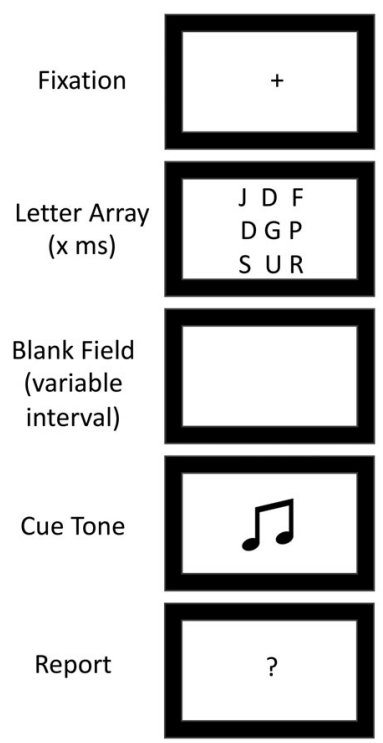

F I G U RE 2 The Partial Report Paradigm used in Sperling (1960)

the phenomenon. The guiding thought is this: In order to make sense of the aforementioned results, we require an explanation for the visual system's comparatively high storage capacity. Specifically, we need to understand how the visual system succeeds in representing all (or 
nearly all) of the items in the array (and their features [Bronfman, Brezis, Jacobson \& Usher, 2014]), while other systems (e.g., those involved in conceptualisation) do not. Iconicity is appealed to for this purpose. By having parts of a single visual icon function like parts of a photograph, these could serve to depict different items in the array (e.g., individual letters or letter shapes), their spatial relationship to one another and their various low-level properties (e.g., their colour and shape). In so doing, information about these items, their parts and their properties could be rendered explicit and accessible to the systems involved in conceptualisation. And yet, the number of depicted letters would hereby fail to dictate the intrinsic complexity of the representation. So, in the same way that a photograph, like Figure 1, depicting a single individual, might have just as easily depicted each and every individual in the entire Rutgers philosophy department (i.e., without requiring that it-the photograph-be bigger, involve more pixels, or take longer to develop), the same could be true of a visual icon depicting all the letters in one of Sperling's arrays. Parts of the representation could simply depict parts of the array, irrespective of whether they contained an entire letter, letter part or empty space. So, if the relevant visual representations were iconic, and PP-conforming, like Figure 1, while the representations involved in conceptualisation were not, then this could explain the comparatively high storage capacity of the former.

To emphasise, I am not assuming that this is the correct way to think about these findings (this is a substantive suggestion in need of substantive defence). The important point for our purposes is that when theorists take iconicity to explain the high storage capacity of visual representations (in the above way) they make an in-eliminable appeal to PP-conformity. Since the notion of "iconic representation" that is employed in the cognitive sciences was coined to formulate explanations of precisely this sort (Neisser, 1967; see Fodor, 2007), and since the assumption that icons conform to PP underwrites appeals to iconic representation more generally-for instance, when explaining rotation effects in mental imagery (see Kosslyn et al., 2006, p. 82), ${ }^{5}$ and illusory inferences in human reasoning (see Johnson-Laird, 2001, p. 434)—PP should be deemed a necessary condition on a representation's iconicity. A representation that does not function as though it has parts depicting parts of the entities depicted (and their spatial relationship to one another) fails to belong to the representational kind that cognitive scientists (employing the term "icon" in their theorising) find useful to denote.

\section{3 | ARE ANALOGUE MAGNITUDE REPRESENTATIONS (AMRs) ICONIC?}

The preceding remarks do not provide an exhaustive characterisation of "iconic representation." As Fodor (2007, p. 109) observes, icons possess a "galaxy" of distinguishing features. ${ }^{6}$ I have simply noted one: PP. Nevertheless, this will suffice for present purposes. If a representation must conform to PP to qualify as iconic, then a representation that fails to do so fails to qualify as such.

\footnotetext{
${ }^{5}$ Kosslyn et al. (2006) describe the relevant representations as "depictive" rather than "iconic." However, these terms are intended to be interchangeable (see, Block, forthcoming; Carey, 2009, p. 458; Quilty-Dunn, forthcoming).

${ }^{6}$ Fodor (2007) states that, in addition to PP, icons are distinctive in their "homogeneity," their inability to express negative, hypothetical or quantified propositions, and their inability to "represent as." Green and Quilty-Dunn (2017) propose that, in addition to PP, icons are distinctive in that they represent properties "holistically" (see also Burge, 2014; Dretske, 1981). Kosslyn et al. (2006) seem to endorse all the above and suggest that icons represent by resembling the entities they represent, and through composing of points representing colour, size and intensity.
} 
Carey recognises this. Like others, she deems PP a defining feature of iconic representation (Carey, 2009, p. 135) as it applies to the aforementioned phenomena (p. 458). But, as we will now see, this raises problems for her proposal that core systems produce iconic outputs. Recall that Carey's case for thinking this stems from her suggestion that certain core representations surely take this form, specifically those produced by the analogue magnitude system. Taking the iconicity of these representations to be well established, she then speculates that other core systems produce representations of this sort. But, while others object, finding this generalization from a single example unsatisfactory, Carey faces a more fundamental problem: Even the AMRs, that are meant to exemplify the iconicity of core representation, seem unlikely to conform to PP. So even here it is unlikely that core cognition is iconic.

\section{1 | Analogue magnitude representation}

The analogue magnitude system is one of two core number systems Carey posits (Carey, 2009, Chapter 4). It is distinctive in that its ability to accurately perform numerical comparisons approximates conformity to Weber's law. Thus, its ability to discriminate the numerosity of two sets is predicted by the ratio between these, rather than their absolute difference in cardinal value. As such, an analogue magnitude system that is capable of reliably making 7:8 discriminations will tend to:

- Do as well discriminating sets of 35 from sets of 40 as it does discriminating sets of seven from sets of eight.

- Do better discriminating sets of 35 from sets of 40 than it does discriminating sets of eight from sets of nine.

- Do worse discriminating sets of 40 from sets of 45 than it does discriminating sets of seven from sets of eight.

In each case, performance is predicted by the ratio's proximity to 1:1 (the further the better), irrespective of how big the sets are. Moving forward, I will refer to this as the system's "signature limit."

It is relatively uncontroversial that humans possess an analogue magnitude system of this sort. Numerous studies indicate that human infants' numerical comparisons are constrained by Weber's law (Wood \& Spelke, 2005; Xu \& Spelke, 2000) and continue to be throughout the lifespan (Barth, Kanwisher \& Spelke, 2003). In each case, the processes involved doubly dissociate from other numerical abilities (Krajcsi, Lengyel \& Kojouharova, 2018; Lemer, Dehaene, Spelke \& Cohen, 2003) and give rise to judgement-independent numerical illusions (Burr \& Ross, 2008; Ginsburg, 1976). This suggests that they result from a genuine (domain specific) system (Mandelbaum, 2013; Walsh, 2003).

It is also widely accepted that this system's signature limit derives from the format of its representations (e.g., Beck, 2015; Condry \& Spelke, 2008; Dehaene, 2011; Feigenson, Carey \& Hauser, 2002; Feigenson, Dehaene \& Spelke, 2004; Lipton \& Spelke, 2003; Slaughter, Kamppi \& Paynter, 2006). There are various reasons for this, pitched at various levels of analysis (see Nieder \& Miller, 2004). Carey's rationale is as follows. She proposes that if the analogue magnitude system were to use representations with what I will call an "analogue structuring," wherein properties of the vehicle serve to represent values (e.g., numerosities) by varying as a monotonic and approximately linear function of these (see Beck, 2015), then 
F I G U RE 3 The lines corresponding to ' 1 ' and '2' are easier to discriminate in length than the lines corresponding to ' 8 ' and ' 9 '

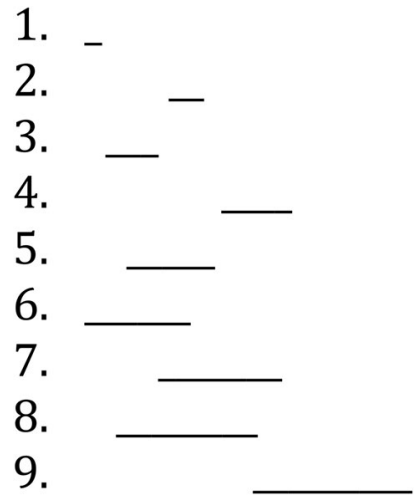

the system's ability to discriminate numerosities could be expected to conform to Weber's law (Carey, 2009, p. 118).

Carey relies on an analogy to motivate this suggestion. Considering "external analogues" of number, like the line lengths found in Figure 3, she claims "it is easy to see that the lengths that represent numbers 1 and 2 should be more discriminable than those that represent 7 and 8 " (Carey, 2009). Thus, she suggests that a system using functional analogues of these line lengths would (or could) be similarly limited.

Carey does not explain precisely why this should be. However, her proposal is typically seen to rest on the (reasonable) assumption that noise would accumulate when a system, employing analogue representations of this sort, were to produce representations of comparatively large numerosities (see Dehaene, 2011). To illustrate, suppose a system actually used line lengths, like those in Carey's example, to represent the number of individuals in a given set by having these lines vary in length as a monotonic and approximately linear function of numerical values being represented. To an approximation, "1" would then be represented by a one-unit long line (e.g., “_"), “2” by a two-unit long line (e.g., “_”) and so on. But since there would always be noise in the system (however little) individual units of line would vary in length to some degree. For instance, a system of this sort might produce individual units of line that vary between 2 and $3 \mathrm{~cm}$ in length due to noise inherent in their production. Here, a one-unit long line representing "one" could be anywhere between 2 and $3 \mathrm{~cm}$ in length, while a line representing "two" would be between 4 and $6 \mathrm{~cm}$ in length. This would allow a suitable consumer system to reliably discriminate these (representations of 1 and 2) since the vehicles would reliably differ in marked ways. But, contrast this with a line representing "three"-which could be between 6 and $9 \mathrm{~cm}$ in length-and a line representing "four"-which could be between 8 and $12 \mathrm{~cm}$ in length. Here, accumulated noise would lead to potential overlap in the vehicles' content-bearing properties. As a result, there would be a range of cases in which the vehicles would end up indistinguishable from the perspective of their consumer system. For instance, an 8-9-cm-long line might represent three or four, with there being no way for the system to tell which. ${ }^{7}$

I leave it as an exercise for the reader to consider other values. The point to note is that, when one does so, discriminability consistently decreases to the extent that the ratio between represented numerosities approximates 1:1. This is true irrespective of how big the represented

${ }^{7}$ In reality, there are likely to be multiple sources of noise involved (see Treisman, 1964). Thus, this is a simplification. Nothing I say turns on this, however. 
numerosities are, and independently of how noisy we suppose the system to be (less noisy systems will simply discriminate tighter ratios). What is important is that the analogue structuring of these representations (the fact that the content-bearing properties of their vehicles represent the numerical values they do by varying as a monotonic and approximately linear function of these) allows us to see why these representations would accumulate noise when representing larger numerosities, rendering them less discriminable and implying conformity to Weber's law in a consumer system's discriminations. Since this is the signature limit we are trying to understand, Carey proposes that the analogue magnitude system is a system processing representations of this sort, and that this explains its performance profile in numerical discrimination tasks.

\subsection{Does this imply iconicity?}

There is reason to be sympathetic to Carey's suggestion. Positing representations with an analogue structure offers to neatly explain the analogue magnitude system's signature limit. So, pending a better explanation, the proposal should be taken seriously. That said, none of the above mentions PP. This is notable since Carey takes AMRs to exemplify the iconicity of core representation, and, as she acknowledges, PP-conformity is constitutive of a representation's qualification as such.

For Carey, PP-conformity falls out of the above suggestion. Thus, she proposes that analogue representations of the above kind collapse into a form of PP-conforming icon. For her, an AMR representing "three" can be thought of as functionally equivalent to a spatially extended line, which is three-units long. As Carey notes, magnitudes of this sort (line lengths) can be sliced up into smaller magnitudes (shorter lines) and, as she frames matters, these will, themselves, represent smaller numerosities since, here, an AMR's represented numerosity is proportional to its size. So, in the same way that a three-unit long line (__ might be sliced up into a two-unit long line (_), which would represent "two" in and of itself, and a one-unit long line (_), which would represent "one" in and of itself, the same is assumed true of the analogue vehicles that are (by hypothesis) involved in AMR. Holding that two and one are parts of three, and that the relationship between the parts of the representation carrying these contents would respect "actual numerical relations" between one, two and their sum, three, PP is seen to follow (Carey, 2009, p. 135).

On these grounds, Carey proposes that AMRs are PP-conforming icons (2009), of the sort posited elsewhere in cognitive science (p. 458). But this is too quick. An initial concern is that the intuitive plausibility of Carey's suggestion derives from the particular example she has used to illustrate her proposal; namely, line lengths. Line lengths do possess parts of a sort that could sustain part-related content. But Carey is not suggesting that people literally have lines in their heads. Rather, she is suggesting that if AMRs were to function like lines in the head then this could explain the signature limit under consideration. The trouble is, there are countless other magnitude and intensity types that would serve Carey's explanatory purposes just as well, where it would seem comparatively obscure to posit parts of the relevant sort, and to thereby assume PP-conformity.

Take speed. Since the speed of an object could correspond to a set's numerosity in the way Carey's line lengths do-by varying as a monotonic and approximately linear function of this-we can conceive of a system that uses one or more objects' speeds to represent numerosities, in an analogue fashion. By Carey's lights, this system's numerical 
discriminations would still conform to Weber's law. For, if a single unit of speed (e.g., $1 \mathrm{mph}$ ) imparted one unit of numerosity (e.g., 1 or 1 ish) onto the representation's total content, but units of speed remained noisy in the way individual units of line length would in Carey's example (as would plausibly be the case) total noise levels would increase when larger numerosities were represented. Thus, the system's discriminations would be constrained in precisely the same way, and for precisely the same reason, as Carey's hypothetical system using line lengths - in both cases this would fall out of the representations' analogue structuring. Yet, quite unlike the system using line lengths, it would seem comparatively obscure to assume that the vehicles would hereby possess parts of the sort required by PP. After all, it is unclear that an object's speed would literally be composed of smaller speeds that would be concrete parts, in and of themselves, that could carry accessible standalone content in the way parts of a line or photograph might. For instance, it is unclear that a speed of $60 \mathrm{mph}$ (depicting 60 or 60 ish) should literally be composed of two individual $30 \mathrm{mph}$ parts, which might each be taken to represent 30 or 30 ish, in and of themselves. But, unless something of this sort were so, PP would not follow, despite the representations having an analogue structure of the relevant sort.

Carey might respond by insisting that speeds (and related magnitudes/intensities) really do possess parts of the relevant sort (e.g., individual parts that are, themselves, slower speeds and which would, thereby, represent numerosity by precisely the same principles as the speed they compose). This would require her to delve into the metaphysics and mereology of speeds (and related magnitudes/intensities). But even if these arguments were forthcoming, Carey's argument for PP-conformity would remain problematic.

Consider the existence of continuous (or approximately continuous) properties, like hue, which vary across non-linear, circular spectra (see Figure 4). Properties of this sort (or their functional analogues) could also be employed by an analogue magnitude system in much the same way as Carey's line lengths. For instance, we can conceive of a system in which numerosity is represented by a light bulb's hue and, specifically, by that hue's distance from some (arbitrary) point on the hue wheel (e.g., from the Green-Yellow boundary in Figure 4). Here, the system's representations would, once again, exemplify the analogue structuring that is relevant to our explanation of the analogue magnitude system's signature limit (represented numerosity would still vary as a monotonic and approximately linear function of hue, allowing noise to accumulate as larger values are represented). But, while it may be obscure to think that the hue would, itself, possess parts, it is important to note that, even if it did, ${ }^{8}$ this would still fail to imply the PP-conformity of the representations. Since the hue wheel is circular, distance could be measured from any arbitrary point. So, even if a light's hue, $\mathrm{H}^{1}$, were to literally possess the hues $\mathrm{H}^{2}-\mathrm{H}^{\mathrm{n}}$ as its proper parts, it is hard to see what would ensure that these parts would stand for parts of the numerosity being depicted by $\mathrm{H} 1$; in principle, these could depict numerosities far greater than $\mathrm{H} 1$ or no numerosities at all (perhaps the system only uses a portion of the hue wheel). Thus, there would be nothing to ensure that the structural relations between parts of the representation would map onto structural relations between the parts of the numerosity being depicted and nothing to ensure the PP-conformity of the representation.

\footnotetext{
${ }^{8}$ For example, even if the vehicle's hue simply amounted to the dominant wavelengths of light it emitted/reflected, and these dominant wavelengths had wavelengths (that would be hues, in and of themselves) as parts.
} 


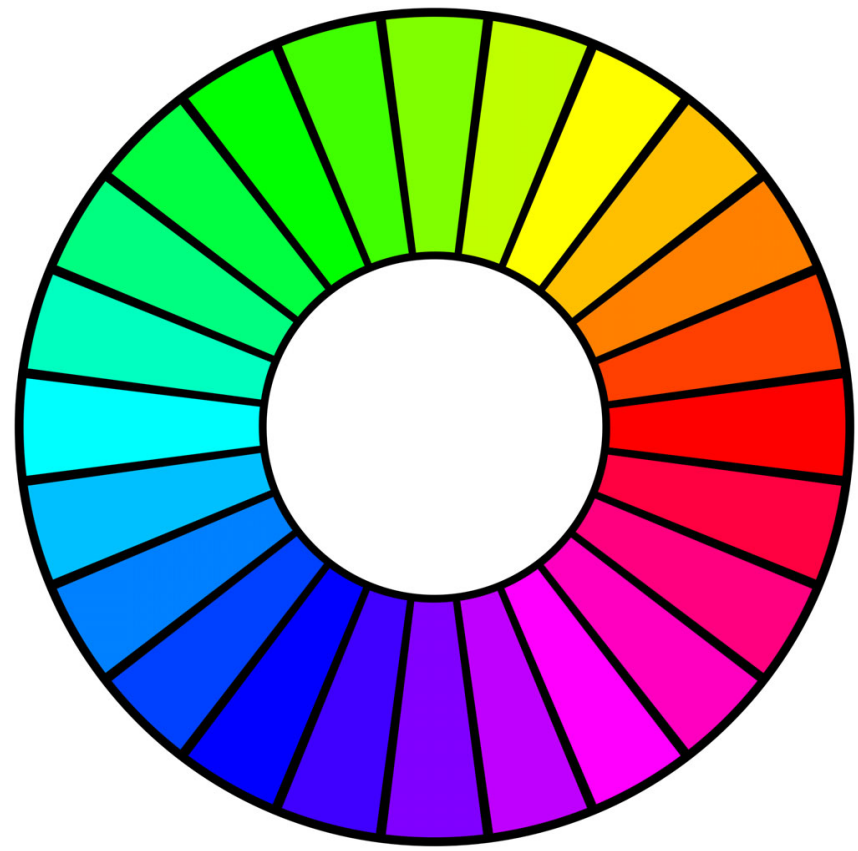

FIGURE 4 The hue wheel [Color figure can be viewed at wileyonlinelibrary.com]

There is also nothing about Carey's explanation that requires that it be an increase in the AMRs content-bearing property that signals an increase in the numerosity being depicted. In principle, a decrease in the relevant content-bearing property could do just as well (particularly if there are arbitrary limits on the numerosities AMRs can depict-see Nieder, 2016). Thus, we can imagine a system that begins with a full barrel of water and keeps count of coconuts by removing a cupful of water each time a coconut is found. Here, smaller quantities of water would signal larger numbers of coconuts in an analogue fashion (i.e., represented numerosity would still be varying as a monotonic and approximately linear function of water volume). But, assuming that there would be noise in the removal process (i.e., that " $a$ cupful" would vary in quantity to some degree) noise would-in this case-accumulate as more cupfuls were removed and as water volume in the barrel decreased. Thus, the absolute quantity of water left in the barrel after three coconuts had been counted would be less well differentiated from the amount of water left in the barrel after four coconuts had been counted than the amount of water left in the barrel after just two coconuts had been counted. As a result, a suitable consumer system, performing its numerical comparisons on the basis of these physical quantities, would still approximate conformity to Weber's Law for much the same reason as Carey's hypothetical system using line lengths. But since smaller volumes of water would here be representing larger numerosities, the representational vehicles would not have parts that would represent parts of the numerosities being depicted. If anything, parts of the content-bearing bodies of water would depict larger numerosities than the vehicle as a whole (i.e., precisely those numerosities that are not parts of the numerosity being depicted). So, while the analogue structuring of the vehicles would still explain why a consumer system's discriminations would conform to Weber's Law (or an approximation thereof), it would be natural to think of the vehicles as representing the values they do in abstraction from any part-related content. 


\subsection{AMRs are (probably) not iconic}

These considerations recommend agnosticism. They do not show that AMRs fail to conform to PP. They simply show that this does not follow from the considerations Carey provides. ${ }^{9}$ There is, however, independent reason to doubt this.

To appreciate why, consider how we might assess the claim that AMRs conform to PP in the way Carey recommends. Ideally, we would examine the vehicles themselves. But what might these be? One possibility is that they are found at the implementation level, in the wetware of the brain. At times, Carey seems sympathetic to this suggestion, writing that while "We do not know how [AMRs] are actually instantiated in the brain" it is possible that "larger quantities could be represented by more neurons firing" (Carey, 2009, p. 458). What is nice about this suggestion is that it highlights a way in which neural findings might evince the PP-conformity of AMRs. After all, if represented numerosity were simply a function of the number of neurons firing within a given population (with increasing numbers of neurons depicting everlarger numerosities) it may be natural to suppose that subsets of this neural population would depict parts of the numerosity depicted by the population as a whole. Unfortunately, this is not what we find when we look to the relevant neuroscience. Rather, neurons in the intraparietal sulcus (IPS) - the presumed home of the analogue magnitude system-are tuned to specific numerosities. Thus, a neuron that is tuned to fire in response to " 5 " (or " 5 ish") will fire most reliably in response to five observed objects, but occasionally fire in response to four and six observed objects (and perhaps even three and seven objects) with neural firing patterns growing increasingly noisy when larger numerosites are depicted (Nieder \& Miller, 2003, 2004).

As Beck (2015) points out, this is "exactly what one would predict given Weber's law; as the ratio of two magnitudes approaches 1:1, the activation patterns of the neurons corresponding to those magnitudes become harder to tell apart" (p. 836). However, it is not what PP-conformity predicts. Specific neurons simply represent an overall value (albeit noisily). So, when neurons encoding 10 or 10 ish fire it is not true that neurons encoding relevant parts of the numerosity (e.g., neurons representing 1-9) must also fire. And, even when they do (due to noise in the signal) this fails to distinguish them from neurons depicting comparably proximal numerosities, which are not parts of the value depicted (e.g., neurons representing 11-19). So, while Carey highlights a possible means by which neural firing patterns could have evinced the PP-conformity of our AMRs, the data points in the opposite direction.

Behavioural findings support this contention. To illustrate, note there are two sides to PP. As the preceding discussion makes clear, a representation can fail to conform to PP because its vehicle does not possess parts that represent parts of the entities being depicted by the

\footnotetext{
${ }^{9}$ Carey might seek independent reasons to endorse the iconicity of AMRs. Quite what these would be remains to be seen. However, an obvious suggestion should be dismissed. Carey might emphasise the fact that icons can be used to explain the avoidance of item effects (see Section 1). Given that the analogue magnitude system is able to perform accurate numerical comparisons in accordance with Weber's law whether the sets under comparison contain 50 individuals or just 10, she might claim that this offers independent reason to posit iconic underpinnings. This would be a mistake. For Carey, the analogue magnitude system is supposed to be a modular system that operates independently of lower-level input systems. So, while lower-level perceptual systems might provide inputs to the system, it functions to produce and operate on representations (AMRs) that abstract away from these lower-level contents. Thus, we need only suppose that the low-level input systems produce representations that avoid item effects of the relevant sort (i.e., those systems that Carey thinks we have independent reason to think produce iconic representations). Provided that these encode the total number of individuals in an observed set, without incurring an item effect, information about set numerosity could simply be read off from these by the analogue magnitude system, enabling it to produce AMRs accordingly.
} 
representation as a whole. However, a representation can also fail to conform to PP if its contents are not represented as having parts. So, in the same way that AMRs will not conform to PP if realised by vehicles without parts, they will not conform to PP if independently depicting entities in this way.

As such, it is worth noting the range of properties AMRs represent and facilitate comparison of. As Carey acknowledges, these are not limited to numerosities, but include a range of "continuous quantities and intensities," like "spatial length, duration, brightness, temperature and loudness" (Srinivasan \& Carey, 2010, p. 218). Speed and pitch could be added to the list (Burge \& Geisler, 2015; Möhring, Ramsook, Hirsch-Pasek, Golinkoff \& Newcombe, 2016). In each case, discriminability approximates conformity to Weber's law. Indeed, discriminability often remains constant across cases, suggesting a degree of functional overlap in the processes and representations involved. For instance, 6-month-olds are unable to discriminate numerical sets unless these have a ratio of 1:2 (Xu \& Spelke, 2000) and these ratio limits are echoed in infants' abilities to discriminate other magnitude types. Thus, six-month-olds discriminate relative distances and speeds but only if they differ by a ratio of at least 1:2 (Möhring, Libertus \& Bertin, 2012), with evidence that this is also true of intensities, like brightness and pitch (Möhring et al., 2016).

By Carey's admission, this suggests a common format type is involved in all these cases (Srinivasan \& Carey, 2010, p. 220). However, this places pressure on her conjecture that numerical AMRs conform to PP. Why? Because it is unclear why we would think this true of other AMRs (which, by hypothesis, share a common format type). For, while some magnitude types, represented by AMRs, seem to possess parts that parts of a relevant representational vehicle might unproblematically represent (e.g., length and duration), this is an obscure suggestion in other cases. For instance, we have already noted that it is non-obvious that speeds possess parts in the way spatially extended line lengths do. At the very least, the suggestion that they do seems metaphysically loaded. ${ }^{10}$ And this should give those endorsing their PP-conformity pause for thought. For when discussing the contents of perceptual representation, theorists typically wish to avoid proposing that perceptual contents take a stand on "arcane" metaphysical issues insofar as this is possible (Farrenikova, 2013; Helton, 2018). But, given the above, this is precisely what the PP-conformity of an AMR representing, for example, speed or brightness would do; since the mereology of these magnitudes/intensities is debatable, postulating PP-conformity has the potential to leave the relevant AMRs forever misrepresenting reality in some significant sense (indeed, given the conclusions of Section 3.2, it runs the risk of doing so needlessly).

Carey might respond that even if AMRs do not conform to PP, themselves, they could remain holistically bound to iconic representations that do. For instance, she might note that parts of paradigmatic icons, like Figure 1, often depict properties like the brightness of points on the depicted entity (see Figure 1) without depicting any individual parts of the brightness (the brightness of each point on Fodor's face seems to be presented at once). So, even if it were true that AMRs fail to conform to PP while representing brightness, speed or the like, and nothing else she may respond that there is no obscurity to the thought that magnitudes/intensities of this problematic sort get represented iconically provided that their representation is holistically bound to the representation of other part-sustaining properties and objects, within a larger perceptual icon. ${ }^{11}$

\footnotetext{
${ }^{10}$ Similar points may apply to intensities such as brightness, loudness, temperature and pitch, particularly if one emphasises spatial parthood when understanding PP (Beck, 2018; Peacocke, 2019).

${ }^{11}$ This would already mark a retreat for Carey. For her, AMRs are supposed to be iconic, in themselves. But, here, AMRs would merely be dimensions of variation within larger perceptual icons.
} 
Unfortunately for Carey, even this is questionable. Numerical analogue magnitude systems operate in an amodal fashion, suggesting that their representations abstract away from lowerlevel (and more plausibly PP-conforming) contents of perception. For example, a classic study by Church and Meck (1984) showed that rats differentiate the total number of heard tones in two sequences, provided that these numerosities differ by a suitably large ratio. This suggested that rats have an operational analogue magnitude system, capable of processing numerical content. And, interestingly, once trained to respond to the numerosity of tones heard, the rats would immediately generalize from this auditory pattern to the visual modality when presented with seen flashes of light (and vice versa). Similar findings have been observed in humans (e.g., Cattaneo, Fantino, Tinti, Silvanto \& Vecchi, 2010), and perhaps even with AMRs representing intensities like pitch, which seem modality specific (Weis, Estner, van Leeuwen \& Lachmann, 2016). This suggests that while analogue magnitude systems take low-level sensory icons as input, they produce and then operate on AMRs that abstract away from, and operate independently of, these. Thus, their representation appears to be syntactically distinct from the representation of low-level properties/happenings in perception.

Furthermore, it is widely accepted that a cortical circuit in the IPS not only facilitates the AMR of numerosities and distances (see Dehaene, Piazza, Pinel \& Cohen, 2003) - that is, things that may be straightforwardly represented as part-sustaining-but also the representation of magnitudes such as brightness and speed, which appear to be represented as lacking parts in the relevant way (Cohen Kadosh et al., 2005; Cohen Kadosh \& Henik, 2006). Interestingly, while this circuit is widely acknowledged to serve a dedicated function-AMR (Dehaene et al., 2003; Walsh, 2003) - it realises this function by representing magnitudes/intensities in abstraction from lower-level perceptual representations. This is evinced by the fact that the magnitudes/intensities that the IPS facilitates comparison of are represented elsewhere, by lower-level perceptual systems. For example, V4 appears sufficient for the visual representation of brightness (Roe et al., 2012) while V5 appears sufficient for the visual representation of speed (Hess, Baker \& Zihl, 1989). This suggests that the IPS does not contribute to the representation of these properties within the visual scene, but serves an independent function. For converging evidence that this is correct, note that lesions to the IPS can selectively inhibit AMR, while leaving the visual representation of the magnitudes/intensities AMRs depict intact (Gliksman, Naparstek, Ifergane \& Henik, 2017). These considerations provide further evidence that the analogue magnitude system represents magnitudes in abstraction from low-level perceptual contents. In this way, we find reason to doubt that AMRs are (themselves) iconic, and reason to doubt that they are holistically bound to the better-established icons of low-level perception.

\section{4 | PERCEPTION AS ANALOGUE}

Given the above, we should probably reject Carey's suggestion that AMRs are iconic. PP-conformity is necessary for a representation's iconicity (Section 2), but AMRs seem unlikely to so conform (Carey's argument that they do is unconvincing (Section 3.2), and there is independent reason to think they do not (Section 3.3)). But, if this is correct, then Carey's characterisation of core cognition, on which core systems are marked by the iconicity of their representations, must be rejected. Indeed, since Carey's case for positing iconicity as a mark of the kind involves generalising from the suggestion that AMRs surely take this form, it is unclear whether any core systems should be expected to produce representations of this sort. 
This sounds like bad news for Carey, and for those who have deemed core systems perceptual (in part) due to the iconicity of their outputs. However, I would like to close by suggesting that this presents them with an opportunity. To see why, note that while we should probably reject the suggestion that AMRs conform to PP, and qualify as candidate icons, we should recognise that they are icon-like in certain respects. Most importantly, both icons and AMRs appear to be analogue insofar as their representational vehicles represent properties and happenings via an exploitable mirroring relation. For instance, both icons and AMRs appear to be analogue in that the content-bearing properties of their vehicles represent the properties and happenings they do by varying as a monotonic (and approximately linear) function of these (see Beck, 2015, pp. 838-839).

This limits the range of properties and happenings that an analogue representation might depict. Loosely, it constrains the domain of analogue content to the depiction of magnitudes, intensities and scalar values. Nevertheless, it is this notion of an analogue representation that is relevant to the above examples, where it is a format of this sort that explains why a suitable consumer system would approximate conformity to Weber's law when performing numerical discriminations. This is because it is an analogue structuring that enables us to see how a representation could naturally accumulate noise in a way that would shed light on the analogue magnitude system's signature limit (at least under certain circumstances). And yet, since this allows that analogue vehicles might fail to conform to PP, it suggests that the relevant notion of an analogue representation being appealed to constitutes a broader category of representation than the purely iconic; that icons are but a sub-category of this broader analogue kind.

To appreciate why this might matter, consider the issue with which we began, the idea that core systems belong to a perceptual kind that is demarcated by the format of its representational outputs (henceforth the common format hypothesis). Traditionally, proponents of such a view frame their hypotheses in terms of an iconic format, deeming it constitutive of the perceptual that its outputs be iconic (Block, 2014; Carey, 2009, 2011). Opponents have then objected, proposing that certain core/perceptual outputs are non-iconic, before taking this to show that a representational format fails to demarcate the kind (e.g., Quilty-Dunn, 2016, p. 262). But as should now be clear, the non-iconicity of these representations need not imply that that they are non-analogue. Thus, our discussion of the analogue magnitude system suggests that appealing to a broader analogue format type may provide a more accommodating means of framing matters.

\section{1 | Avoiding (otherwise troubling) objections}

An initial reason why it might prove fruitful to frame common format hypotheses in terms of an analogue (but not necessarily iconic) format concerns the fact that this may avoid otherwise troubling objections posed by perceptual and/or core representations that are not clearly iconic. For instance, while it may be plausible to think of certain paradigmatically visual, tactile and perhaps auditory representations as PP-conforming icons (Fodor, 2007), it is less clear that this will apply to other modalities, like olfaction or gustation. On the view that these modalities produce genuinely perceptual representations, of a sort that the common format hypothesis should seek to accommodate (Smith, 2015; contra Burge, 2010), this is a worry insofar as the view is framed in terms of iconicity. It is, however, a worry that could be straightforwardly avoided if the hypothesis were framed in terms of an analogue format. Here, the view would not be committed to the relevant representations' PP-conformity. It would simply be committed to the 
represented intensities mirroring some vehicular property (functional or neurophysiological) in the appropriate way. And given that the discrimination of the intensities detected through olfaction and gustation has long been found to approximate conformity to Weber's law (Stone \& Bossley, 1965), in a way that analogue representations have been seen to explain (Section 3), it is a suggestion that enjoys independent plausibility. Thus, a common format hypothesis framed in terms of analogue representation appears better placed to characterise the format of perceptual representations, if proponents hope to characterise modalities beyond vision, touch and audition.

It is also possible that appealing to an analogue format will help defuse worries with the iconicity of core object representations. These representations have recently been deemed "the most striking" counterexample to a common format hypothesis (Quilty-Dunn, forthcoming, p.11). To get a taste for why, consider Green and Quilty-Dunn (2017) who draw attention to the "multiple object tracking" (MOT) paradigm. Here, subjects are found able to keep track of (roughly) four to five visible objects, as they move around an array, in a way that abstracts away from their shape, size and colour (see Pylyshyn, 2003). According to Green and Quilty-Dunn, this suggests that the representation of an object in the visual field must remain syntactically separate from the representation of its parts and the representation of its low-level properties (a point of dis-analogy with paradigmatic icons, like Figure 1, and a finding deemed inconsistent with the PP-conformity of these representations). ${ }^{12}$ But note, even if this is correct, and this renders the relevant representations non-iconic, the fact that PP-conformity is not necessary for a representation to qualify as analogue (in the above sense) reveals that this need not be relevant to the truth of a common format hypothesis framed in my recommended terms. Here, the important question is not "do these representations conform to PP (and the like)?" it is simply "are these representations analogue in the above sense?"

This is a modest point. Nevertheless, it bears emphasis. While subjects fail to recall the spatio-temporal criteria used to individuate and track objects in MOT paradigms, task competence does demonstrate subjects' abilities to keep track of objects' spatially extended locations in the perceptual field (Feigenson et al., 2002; Scholl, Pylyshyn \& Franconerri, 1999). This is notable since the perception of spatial extension and spatial location are precisely the sorts of properties that one might expect to be mediated by analogue representations. After all, the perceptual representation of space (and spatial location) appears to be finegrained and unit-free (Evans, 1982; Peacocke, 1986) which has long been deemed indicative of non-conceptual, analogue underpinnings (Beck, 2018; Tye, 1991). Thus, it is plausible that representations with the analogue structure of AMRs function to pick out individual objects in the perceptual field by specifying their locations, and perhaps even function to represent these as individuals whether or not they conform to PP, qualify as iconic or take a stand on part-related content of the objects depicted. As such, appreciating the possibility that a common format hypothesis might be framed in terms of a broader analogue format type could (potentially) defuse objections to versions of the hypothesis framed in terms of iconicity.

\footnotetext{
${ }^{12}$ Green and Quilty-Dunn suggest an even deeper problem is posed by findings from the Object Reviewing Paradigm, wherein discursive labels are bound to these perceptual object representations (Kahneman et al., 1992). However, proponents of a common format hypothesis (e.g., Block, forthcoming) deny that these actually reflect the operations of perceptual/core object systems, suggesting that their status as perceptual remains an open question.
} 


\section{2 | Distinguishing perception from cognition}

A further motivation for framing common format hypotheses in my recommended terms concerns the tenability of thinking that central cognition may (in some important sense) remain non-analogue, by proponents of common format hypotheses' lights. So, if it were found that perception is analogue then this could potentially mark a perception-cognition border.

To see this, note that proponents of a common format hypothesis often hold that central cognition processes representations with a distinctively language-like format (Block, forthcoming; Carey, 2009). This is of course controversial (Dennett, 1978), and there may be various ways of characterising the suggestion. ${ }^{13}$ Nevertheless, language-like representations are often posited in cognition to explain why systematic relations obtain between thoughts (Fodor \& Pylyshyn, 1988; Pinker \& Prince, 1988) as a matter of "nomological necessity" (Fodor \& McLaughlin, 1990, p. 188). Consequently, it is striking that the analogue format of our AMRs could seem to prevent them from entering into genuinely systematic relations of this sort (Beck, 2012, 2015).

Very roughly, mental representations are only systematic if their constituents can be recombined and distinguished in a range of syntactically appropriate ways. Thus, the representations "John loves Mary" and "Jenny hates Matt" are systematic insofar as their constituents can be recombined to produce representations like "Matt hates Mary." But, since the discriminability of two AMRs is constrained by the ratio between the magnitudes they represent, AMRs seem to prevent intelligible re-combinability of this sort. To illustrate, a 6-month old might possess a functioning analogue magnitude system that represents and enables the discrimination of numerosities provided these differ by a ratio of 1:2 (Xu \& Spelke, 2000). Here, the system may enable them to represent a set of approximately 10 as such, a set of approximately five as such, and to represent the former set as bigger than the latter. Similarly, it may enable them to represent a set of approximately seven as such, a set of approximately 14 as such, and to represent the former as smaller than the latter. Nevertheless, it would not enable them to represent the set of approximately five as smaller than the set of approximately seven. But this is precisely what systematicity would seem to demand. Since this is entailed by the signature limit of the system, which is seen to derive from the analogue format of its representations, this seems to imply that the analogue format of our AMRs prevents them from entering into genuinely systematic relations of the sort deemed true of the representations employed in thought.

Fully exploring this possibility would (again) require a dedicated treatment. Nevertheless, it provides further reason to think that a common format hypothesis framed in terms of an analogue (but not necessarily iconic) format deserves consideration. If an analogue format problematizes systematicity, quite generally, then it is plausible to think that central cognition will be importantly non-analogue. ${ }^{14}$ So, despite offering a relatively accommodating means of

\footnotetext{
${ }^{13}$ It is sometimes suggested that these representations are language-like in virtue of having a canonical decomposition (Fodor, 2007; Green \& Quilty-Dunn, 2017). It is not clear that representations containing analogue constituents would fail to qualify by this criterion (Beck, 2015). However, we will now see that there are other ways to distinguish analogue representations from those posited in thought.

${ }^{14}$ There are possible complications lurking hereabouts. One worry derives from the existence of mental imagery (Kosslyn et al., 2006) and imagistic thinking (Johnson-Laird, 2001) which might take place in an analogue format, despite being properly cognitive. There are various ways that proponents of a common format hypothesis might respond. One option is to hold that these representations simply involve the cognitive hijacking of properly perceptual resources (Clarke, 2019). In any case, the proposal being floated fairs no worse than traditional common format hypotheses in this regard.
} 
characterising perception, it is plausible to think that an analogue format could still distinguish perception from central cognition and that a common format hypothesis, framed in these terms, may prove relatively accommodating.

\section{5 | CONCLUSION}

In Section 2, I introduced a necessary condition on the iconicity of a representation (PP), before using this to cast doubt on the suggestion that AMRs are iconic (Section 3). Prima facie, this looked like bad news for Carey, who has sought to characterise core cognition by appeal iconicity, and for theorists who have sought to demarcate a perceptual kind (to which core systems belong) in this way (Block, forthcoming; Burge, 2010). However, I have suggested that this presents them with an opportunity (Section 4). Since AMRs have an analogue format, that subsumes the iconic as a sub-kind, but nevertheless marks them out from the lingua-form representations posited in thought, this provides a relatively accommodating means of framing a common format hypothesis. Framed in terms of analogue representation, a common format hypothesis can accommodate the existence of genuine icons in perception, and avoid prominent objections to the suggestion that all perceptual outputs take this form. There is, of course, much work to be done examining and elaborating this proposal. Nevertheless, examination of the analogue magnitude system suggests this is a live and independently motivated possibility in need of further consideration.

\section{ACKNOWLEDGEMENTS}

For comments and helpful discussion, I am extremely grateful to Greyson Abid, Jake Beck, Dan Burnston, Dan Casey, Laurenz Casser, Lauren Emberson, Justin Fisher, Grace Helton, Michael Martin, Ian Phillips, Jake Quilty-Dunn, Joulia Smortchkova, Mason Westfall, two anonymous reviewers and audiences in Montreal, New York, Oslo, Princeton, Toronto and Washington, DC.

\section{FUNDING INFORMATION}

This research was funded by a Procter Fellowship at Princeton University, an AHRC Doctoral Grant at the University of Oxford and a VISTA Fellowship at York University, Toronto.

\section{ORCID}

Sam Clarke (D) https://orcid.org/0000-0001-8383-0584

\section{REFERENCES}

Barth, H., Kanwisher, N. \& Spelke, E. (2003). The construction of large number representations in adults. Cognition, 86(3), 201-221. https://doi.org/10.1016/S0010-0277(02)00178-6

Beck, J. (2012). The generality constraint and the structure of thought. Mind, 121(483), 563-600. https://doi.org/ 10.1093/mind/fzs077

Beck, J. (2015). Analogue magnitude representations: A philosophical introduction. The British Journal for the Philosophy of Science, 66(4), 829-855. https://doi.org/10.1093/bjps/axu014

Beck, J. (2018). Analog mental representation. WIREs Cognitive Science, 9(6), e1479. https://doi.org/10.1002/wcs. 1479

Block, N. (2014). Seeing-as in the light of vision science. Philosophy and Phenomenological Research, 89(3), 560572. https://doi.org/10.1111/phpr.12135

Block, N. (2021). The border between seeing and thinking. Cambridge, MA: MIT Press. 
Bronfman, Z., Brezis, N., Jacobson, H. \& Usher, M. (2014). We see more than we can report: "Cost free" color phenomenality outside of focal attention. Psychological Science, 25(7), 1394-1403. https://doi.org/10.1177/ 0956797614532656

Burge, J. \& Geisler, W. S. (2015). Optimal speed estimation in natural image movies predicts human performance. Nature, 4(6), 7900. https://doi.org/10.1038/ncomms8900

Burge, T. (2010). The origins of objectivity. Oxford: Oxford University Press.

Burge, T. (2011). Border crossings: Perceptual and post-perceptual object representation. Behavioral and Brain Sciences, 34(3), 125. https://doi.org/10.1017/S0140525X10002323

Burge, T. (2014). Reply to Rescorla and Peacocke: Perceptual content in light of perceptual constancies and biological constraints. Philosophy and Phenomenological Research, 88(2), 485-501. https://doi.org/10.1111/phpr. 12093

Burr, D. \& Ross, J. (2008). A visual sense of number. Current Biology, 18(6), 425-428. https://doi.org/10.1016/j. cub.2008.02.052

Carey, S. (2009). The origin of concepts. Oxford: Oxford University Press.

Carey, S. (2011). Precis of the origin of concepts. Behavioral and Brain Sciences, 34(3), 113-162. https://doi.org/ 10.1017/S0140525X10000919

Cattaneo, Z., Fantino, M., Tinti, C., Silvanto, J. \& Vecchi, T. (2010). Crossmodal interaction between the mental number line and peripersonal haptic space representation in sighted and blind individuals. Attention, Perception, \& Psychophysics, 72(4), 885-890. https://doi.org/10.3758/APP.72.4.885

Church, R. M. \& Meck, W. H. (1984). The numerical attribute of stimuli. In H. L. Roitblat, T. G. Beaver \& H. S. Terrace (Eds.), Animal cognition (pp. 445-464). Hillsdale, NJ: Lawrence Erlbaum.

Clarke, S. (2019). The architecture of perceptual systems. (Doctoral dissertation). University of Oxford, Oxford.

Cohen Kadosh, R. \& Henik, A. (2006). A common representation for semantic and physical properties: A cognitive-anatomical approach. Experimental Psychology, 53(2), 87-94. https://doi.org/10.1027/1618-3169.53. 2.87

Cohen Kadosh, R., Henik, A., Rubinsten, O., Mohr, H., Dori, H., Van de Ven, V., ... Linden, D. E. (2005). Are numbers special? The comparison systems of the human brain investigated by fMRI. Neuropsychologia, 43, 1238-1248. https://doi.org/10.1016/j.neuropsychologia.2004.12.017

Coltheart, M. (1980). Iconic memory and visible persistence. Perception \& Psychophysics, 27(3), 183-228. https:// doi.org/10.3758/BF03204258

Condry, K. \& Spelke, E. (2008). The development of language and abstract concepts: The case of natural number. Journal of Experimental Psychology: General, 137(1), 22-38. https://doi.org/10.1037/0096-3445.137.1.22

Dehaene, S. (2011). The number sense: How the mind creates mathematics. New York, NY: Oxford University Press.

Dehaene, S., Piazza, M., Pinel, P. \& Cohen, L. (2003). Three parietal circuits for number processing. Cognitive Neuropsychology, 20(3), 487-506. https://doi.org/10.1080/02643290244000239

Dennett, D. (1978). A cure for the common code. In Brainstorms: Philosophical essays on mind and psychology (pp. 90-108). Cambridge, MA: Bradford Books.

Dretske, F. (1981). Knowledge and the flow of information. Cambridge, MA: MIT Press.

Echeverri, S. (2017). Visual reference and iconic content. Philosophy of Science, 84(4), 761-781. https://doi.org/ $10.1086 / 693876$

Evans, G. (1982). The varieties of reference. Oxford: Oxford University Press.

Farennikova, A. (2013). Seeing absence. Philosophical Studies, 166(3), 429-454. http:/doi.org/10.1007/s11098-0120045-y.

Feigenson, L. \& Carey, S. (2003). Tracking individuals via object files: Evidence from infants' manual search. Developmental Science, 6(5), 568-684. https://doi.org/10.1111/1467-7687.00313

Feigenson, L., Carey, S. \& Hauser, M. (2002). The representations underlying infants' choice of more: Object files versus analog magnitudes. Psychological Science, 13(2), 150-156. https://doi.org/10.1111/1467-9280.00427

Feigenson, L., Dehaene, S. \& Spelke, E. (2004). Core systems of number. Trends in Cognitive Sciences, 8(7), 307314. https://doi.org/10.1016/j.tics.2004.05.002

Fodor, J. A. (1983). The modularity of mind. Cambridge, MA: MIT Press.

Fodor, J. A. (2007). The revenge of the given. In B. McLaughlin \& J. Cohen (Eds.), Contemporary debates in philosophy of mind (pp. 105-116). Oxford: Blackwell. 
Fodor, J. A. \& McLaughlin, B. (1990). Connectionism and the problem of systematicity: Why Smolensky's solution doesn't work. Cognition, 35(2), 183-204. https://doi.org/10.1016/0010-0277(90)90014-B

Fodor, J. A. \& Pylyshyn, Z. (1988). Connectionism and cognitive architecture: A critical analysis. Cognition, 28 (1-2), 3-71. https://doi.org/10.1016/0010-0277(88)90031-5

Ginsburg, N. (1976). Effect of item arrangement on perceived numerosity: Randomness vs. regularity. Perceptual and Motor Skills, 42(43), 663-668. https://doi.org/10.2466/pms.1976.43.2.663

Gliksman, Y., Naparstek, S., Ifergane, G. \& Henik, A. (2017). Visual and imagery magnitude comparisons are affected following left parietal lesion. Frontiers in Psychology, 19(8), 1622. https://doi.org/10.3389/fpsyg.2017.01622

Green, E. J. \& Quilty-Dunn, J. (2017). (forthcoming). What is an object file? British Journal for the Philosophy of Science. https://doi.org/10.1093/bjps/axx055

Gross, S. \& Flombaum, J. (2017). Does perceptual consciousness overflow cognitive access? The challenge from probabilistic, hierarchical processes. Mind \& Language, 32(3), 358-391. https://doi.org/10.1111/mila.12144

Helton, G. (2018). Visually perceiving the intentions of others. The Philosophical Quarterly, 68(271), $243-264$. https://doi.org/10.1093/pq/pqx051

Hess, R. H., Baker, C. L. \& Zihl, J. (1989). The “motion blind” patient: Low-level spatial and temporal filters. Journal of Neuroscience, 9, 1628-1640. https://doi.org/10.1523/JNEUROSCI.09-05-01628.1989

Johnson-Laird, P. (2001). Mental models and deduction. Trends in Cognitive Sciences, 5(10), 434-452. https://doi. org/10.1016/S1364-6613(00)01751-4

Kahneman, D., Treisman, A. \& Gibbs, B. J. (1992). The reviewing of object files: Object-specific integration of information. Cognitive Psychology, 24, 175-219. https://doi.org/10.1016/0010-0285(92)90007-O

Kosslyn, S. M., Thompson, W. L. \& Ganis, G. (2006). The case for mental imagery. Oxford: Oxford University Press.

Krajcsi, A., Lengyel, G. \& Kojouharova, P. (2018). Symbolic number comparison is not processed by the analog number system: Different symbolic and non-symbolic numerical distance and size effects. Frontiers in Psychology: Cognition, 9(124), 1-16. https://doi.org/10.3389/fpsyg.2018.00124

Lemer, C., Dehaene, S., Spelke, E. \& Cohen, L. (2003). Approximate quantities and exact number words: Dissociable systems. Neuropsychologia, 41(14), 1942-1958. https://doi.org/10.1016/S0028-3932(03)00123-4

Lipton, J. \& Spelke, E. (2003). Origins of number sense: Large number discrimination in human infants. Psychological Science, 14(5), 396-401. https://doi.org/10.1111/1467-9280.01453

Mandelbaum, E. (2013). Numerical architecture. Topics in Cognitive Science, 5(2), 367-386. https://doi.org/10. $1111 /$ tops.12014

Marr, D. (1982). Vision: A computational investigation into the human representation and processing of visual information. Cambridge, MA: MIT Press.

Möhring, W., Libertus, M. E. \& Bertin, E. (2012). Speed discrimination in 6- and 10-month-old infants follows Weber's law. Journal of Experimental Child Psychology, 111(3), 405-418. https://doi.org/10.1016/j.jecp.2011. 11.002

Möhring, W., Ramsook, K. A., Hirsch-Pasek, K., Golinkoff, R. M. \& Newcombe, N. S. (2016). Where music meets space: Children's sensitivity to pitch intervals is related to their mental spatial transformation skills. Cognition, 151, 1-5. https://doi.org/10.1016/j.cognition.2016.02.016

Neisser, U. (1967). Cognitive psychology. Englewood Cliffs, NJ: Prentice-Hall.

Nieder, A. (2016). The neuronal code for number. Nature Neuroscience, 17, 366-382. https://doi.org/10.1038/nrn. 2016.40

Nieder, A. \& Miller, E. K. (2003). Coding of cognitive magnitude: Compressed scaling of numerical information in the primate prefrontal cortex. Neuron, 37(1), 149-157. https://doi.org/10.1016/S0896-6273(02)01144-3

Nieder, A. \& Miller, E. K. (2004). A parieto-frontal network for visual Nnumerical information in the monkey. Proceedings of the National Academy of Sciences of the United States of America, 101(19), 7457-7462. https:// doi.org/10.1073/pnas.0402239101

Peacocke, C. (1986). The inaugural address: Analogue content. Aristotelian Society Supplementary, 60(1), 1-17. https://doi.org/10.1093/aristoteliansupp/60.1.1

Peacocke, C. (2019). The primacy of metaphysics. Oxford: Oxford University Press.

Phillips, B. (forthcoming). The shifting border between perception and cognition. Noûs. https://doi.org/10.1111/ nous. 12218

Pinker, S. \& Prince, A. (1988). On language and connectionism: Analysis of a parallel distributed processing model of language acquisition. Cognition, 28(1-2), 73-193. https://doi.org/10.1016/0010-0277(88)90032-7 
Prinz, J. (2007). Is the mind really modular? In R. Stainton (Ed.), Contemporary debates in cognitive science (pp. 22-36). Oxford: Blackwell.

Pylyshyn, Z. (2003). Seeing and visualizing: It's not what you think. Cambridge, MA: MIT Press.

Quilty-Dunn, J. (2016). Iconicity and the format of perception. Journal of Consciousness Studies, 23(3-4), 255-263.

Quilty-Dunn, J. (forthcoming). Perceptual pluralism. Noûs. https://doi.org/10.1111/nous.12285

Roe, A. W., Chelazzi, L., Connor, C. E., Conway, B. R., Fujita, I., Gallant, J., ... Vanduffel, W. (2012). Toward a unified theory of visual area V4. Neuron, 74(1), 12-29. https://doi.org/10.1016/j.neuron.2012.03.011

Scholl, B. J., Pylyshyn, Z. \& Franconerri, S. L. (1999). When are spatiotemporal and featural properties encoded as a result of attentional allocation? Talk given at the Association for Research in Vision and Ophthalmology, 13th May 1999, Ft. Lauderdale, FL. [Abstract published as: (1999) Investigative Ophthalmology and Visual Science, 40(4), S797.]

Shea, N. (2011). New concepts can be learned. Biology and Philosophy, 26(1), 129-139. https://doi.org/10.1007/ s10539-009-9187-5

Slaughter, V., Kamppi, D. \& Paynter, J. (2006). Toddler subtraction with large sets: Further evidence for an analog-magnitude representation of number. Developmental Science, 9(1), 33-39. https://doi.org/10.1111/j.14677687.2005.00460.x

Smith, B. (2015). The chemical senses. In M. Matthen (Ed.), The Oxford handbook of philosophy of perception (pp. 314-352). Oxford: Oxford University Press.

Spelke, E. (1988). Where perceiving ends and thinking begins: The apprehension of objects in infancy. In A. Yonas (Ed.), Perceptual development in infancy: Minnesota symposium on child psychology (Vol. 20, pp. 197-233). Hillsdale, NJ: Lawrence Erlbaum.

Spelke, E. \& Kinzler, K. D. (2007). Core knowledge. Developmental Science, 10(1), 89-96. https://doi.org/10.1111/ j.1467-7687.2007.00569.x

Sperling, G. (1960). The information available in brief visual presentations. Psychological Monographs: General and Applied, 74(11), 1-29. https://doi.org/10.1037/h0093759

Srinivasan, M. \& Carey, S. (2010). The long and the short of it: On the nature and origin of functional overlap between representations of space and time. Cognition, 116(2), 217-241. https://doi.org/10.1016/j.cognition. 2010.05.005

Stone, H. \& Bossley, J. J. (1965). Olfactory discrimination and Weber's law. Perceptual and Motor Skills, 20(2), 657-665. https://doi.org/10.2466/pms.1965.20.2.657

Treisman, M. (1964). Noise and Weber's law: The discrimination of brightness and other dimensions. Psychological Review, 71(4), 314-330. https://doi.org/10.1037/h0042445

Tye, M. (1991). The imagery debate. Cambridge, MA: MIT Press.

van Buren, B., Gao, T. \& Scholl, B. J. (2017). What are the underlying units of perceived animacy? Chasing detection is intrinsically object-based. Psychonomic Bulletin \& Review, 24(5), 1604-1610. https://doi.org/10.3758/ s1342

Walsh, V. (2003). A theory of magnitude: Common cortical metrics of time, space and quantity. Trends in Cognitive Sciences, 7, 483-488. https://doi.org/10.1016/j.tics.2003.09.002

Weis, T., Estner, B., van Leeuwen, C. \& Lachmann, T. (2016). SNARC (spatial-numerical association of response codes) meets SPARC (spatial-pitch association of response codes): Automaticity and interdependence in compatibility effects. The Quarterly Journal of Experimental Psychology, 69(7), 1366-1383. https://doi.org/10. 1080/17470218.2015.1082142

Wood, J. \& Spelke, E. (2005). Infants' enumeration of actions: Numerical discrimination and its signature limits. Developmental Science, 8(2), 173-181. https://doi.org/10.1111/j.1467-7687.2005.00404.x

$\mathrm{Xu}$, F. \& Spelke, E. (2000). Large number discrimination in 6-month-old infants. Cognition, 74(1), b1-b11. https://doi.org/10.1016/S0010-0277(99)00066-9

How to cite this article: Clarke S. Beyond the icon: Core cognition and the bounds of perception. Mind Lang. 2020;1-20. https://doi.org/10.1111/mila.12315 